\title{
Responsabilidad «ampliada» y juicio moral
}

\author{
MARÍA JOSÉ GUERRA \\ Universidad de La Laguna
}

\begin{abstract}
RESUMEN. El objeto de este artículo es presentar las dimensiones intersubjetivas y objetivas de la responsabilidad que formularon Hannah Arendt y Hans Jonas. La versión jurídica e individual de la responsabilidad como mero correlato de la libertad ha quedado sobrepasada por la magnitud de las consecuencias de la acción humana consignadas en el siglo XX. A título de ejemplo, señalaremos a los totalitarismos, a la crisis ecológica o al impacto de las biotecnologías. Una escala de acción de tales magnitudes exige pensar una responsabilidad «ampliada». Conectar las dimensiones intersubjetivas y objetivas de la responsabilidad con el juicio moral en un modelo complejo y multifactorial es nuestra propuesta aquí.
\end{abstract}

\begin{abstract}
This paper focuses on the intersubjective and objective dimensions of responsibility that were formulated by Hannah Arendt and Hans Jonas. The juridical version of responsibility referred to an individual behaviour is not enough to cope with the new scales of the human action, for example, totalitarisms, the ecological crisis or the impact of biotechnologies. These new problems demand to think an «amplified» or extended concept of responsibility. Our proposal here is to connect the intersubjective and objective's dimensions of responsibility with a complex model of moral judgment.
\end{abstract}

La no participación en los asuntos políticos del mundo ha sido siempre susceptible del reproche de irresponsabilidad, de abandonar nuestros deberes hacia el mundo que compartimos con los otros y con la comunidad a la que pertenecemos (Hannah Arendt).

... las cosas están ya quemándonos los dedos, habrá que empezar por algún sitio y plantear la cuestión de una autocensura de la ciencia bajo el signo de la responsabilidad (Hans Jonas).

El tratamiento analítico del concepto de responsabilidad es hoy una de las tareas más arduas que nos podemos imaginar. Integrar todas sus facetas - subjetiva-intersubjetiva-objetiva, directa e indirecta, individual y colectiva, etc. - y componentes o requisitos - libertad, decisión, imputabilidad...- en una noción coherente y bien armada parece ser, por ahora, una labor enor- 
memente difícil ${ }^{1}$. A este respecto, uno de los datos a consignar es que la estricta comprensión de la responsabilidad como meramente subjetiva queda sobrepasada por las mutaciones en el alcance de las acciones humanas ${ }^{2}$ y por su carácter muchas veces ciegamente concertado por más de un agente. El contestar a la pregunta «¿quién debe responder de esto?» no es, en muchas, si no en la mayoría, de las ocasiones, nada fácil.

El caso es que cuando más escurridiza parece hacerse la atribución clara y distinta de responsabilidad, más necesidad estamos teniendo de repensar analítica y pragmáticamente la misma noción de responsabilidad. En esta presentación voy a centrarme en algunas formulaciones de la idea de responsabilidad, especialmente las de Hannah Arendt y Hans Jonas, que desafían la noción tradicional de la misma. El reto que plantean estos dos autores toma dos rumbos distintos.

En el caso de Arendt la dirección es intersubjetiva y está conectada con dos acotaciones de su idea de responsabilidad: el que somos responsables por el «mundo» - la trama intersubjetiva que nos sostiene y que debemos colaborar a sostener - y la de que, en relación con la anterior, existe un significado, más allá de la mera retórica, para la expresión «responsabilidad colectiva». Arendt presagia el giro intersubjetivo que se ha impuesto en las éticas discursivas. No en vano su teorización ha sido una de las fuentes de inspiración para la idea habermasiana de «acción comunicativa». La responsabilidad, para nuestra autora, muestra, como decíamos, un carácter originariamente intersubjetivo, esto es, somos responsables porque debemos responder ante otros. El responder ante uno mismo, la idea kantiana del tribunal de la conciencia, sería, pues, un fenómeno derivado que debe reconocer el origen intersubjetivo de la misma conformación y emergencia ontogenética de la conciencia moral. A partir de aquí podemos entender la importancia otorgada por Arendt al «juicio político» que consiste, básicamente, en el uso del pensamiento representativo y de la imaginación para «ponerse en el lugar del otro». Arendt sugiere que «evitar el mal» es el objetivo de una facultad de enjuiciar. Pone al juicio, por tanto, al servicio de lo que podríamos llamar hoy sin ambages una ética de la responsabilidad.

El caso de Jonas apunta a otra dimensión de la responsabilidad que él mismo denomina objetiva. Somos responsables, entre otras cosas, de la preservación del planeta y de asegurar condiciones de vida humana libre y digna en el futuro. No podemos mantener la dirección biocida y suicida de nuestra civilización tecno-científica en la que las características de la acción han mutado, puesto que las consecuencias ya no se limitan a un plano local, sino que se expanden globalmente. Frente a este problema, la humanidad

\footnotetext{
1 Cfr. A. Valdecantos, «Teodicea, nicotina y virtud», en M. Cruz y R. R. Aramayo El reparto de la acción. Ensayos en torno a la responsabilidad, Madrid, Trotta, 1999, p. 51.

2 Cfr. P. T. Durbin (ed.), Technology and Responsability, D. Reidel Publishing Company, 1987.
} 
toda se haya concernida y debe hacer algo. Nuestros juicios morales no pueden descontar esta constatación y, por lo tanto, deben invocar nuevos principios para hacernos cargo de las novedades que, en muchos casos, amenazan tanto con arruinar el equilibrio natural como con intervenir y modificar la misma naturaleza humana - un ejemplo de esto sería la intervención biotecnológica propiciada por la secuenciación y el desciframiento del genoma-. Evitar el mal es, también, a este respecto el motor del imperativo de la responsabilidad.

Estas nuevas dimensiones acentúan la necesidad de empezar a prestar atención al carácter intersubjetivo y objetivo de la noción de responsabilidad y de poner al juicio moral al servicio de estas nuevas determinaciones. Una consecuencia derivada de lo anterior podría ser la siguiente: habitualmente ha tenido un peso mayor la responsabilidad por las acciones que por las omisiones, sin embargo, en las actuales condiciones, quizás, seamos más responsables de lo que no hacemos ni emprendemos. Instalados confortablemente en una cultura de la autocomplacencia y de la autoindulgencia los deberes que emanan de la responsabilidad quedarían oscurecidos e invisibilizados. Lipovetsky tendría razón en su diagnóstico de El crepúsculo del deber. Los valores de una sociedad de consumo en los que la autorrealización personal y el bienestar propio son supremos obstaculizan el «hacernos cargo» de los viejos y nuevos problemas. Por ejemplo, estamos poniendo en peligro la supervivencia de la humanidad sobre la tierra por no habilitar medidas contra el cambio climático. Seremos, por tanto, responsables no sólo de arruinar los equilibrios ecológicos, sino de la multitud de víctimas humanas que traerá consigo el fenómeno, sobre todo, en las partes más empobrecidas del planeta. Las omisiones estarían, por tanto, relacionadas, más ahora que nunca, con el no reconocimiento de las dimensiones intersubjetiva y objetiva de la responsabilidad. En este sentido, la pregunta a responder es, pues: ¿de qué somos responsables y ante quiénes? Esta pregunta colisiona, a mi entender, con las extendidas actitudes de repliegue a lo privado, de indiferencia, de apatía y de nítido desentendimiento de los otros, del mundo y de la naturaleza. Las preguntas «ante quién o quiénes soy responsable» $\mathrm{y}$ «de qué soy responsable» deben ser atendidas y despejadas en la elaboración de nuestros juicios morales que, en definitiva, son los que decidirán acerca de si actuar o no y si elegimos hacerlo en qué sentido. El caso es que muchas de las situaciones ante las que debemos responder exigen un juicio elaborado pragmáticamente en la deliberación colectiva en la que participar sería una obligación no objetable. A este respecto, la ganancia obtenida por las éticas dialógicas y por los modelos de democracia deliberativa no puede ser despilfarrada. Debemos de empezar a hablar de una pragmática de la responsabilidad.

Mi punto de partida, en consecuencia, es el siguiente: los modelos de juicio moral deben rendir cuentas ante las exigencias de una ética de la respon- 
sabilidad. No creo, por otra parte, que sea otro motivo que éste el que alienta otro giro de la ética, el que se ha denominado «giro aplicado». Este giro se ha dejado sentir tarde, pero intensamente, en el panorama del pensamiento moral al problematizar diversas esferas de las actividades humanas. No obstante, el volumen de trabajo pendiente a este respecto es abrumador. Las demandas de la ética ecológica, la bioética, la ética de los medios de comunicación, de la economía, etc., no dejan de incrementarse día tras día. Las éticas aplicadas se definen, pues, por su objeto y reconocen en su misma autodefinición la responsabilidad por el sufrimiento humano, la degradación del planeta, el poder de los medios de comunicación, la desigualdad de la riqueza, etc. Responsabilidad y praxis exteriorizan sus vínculos en nuevos contextos reflexivos.

El «giro aplicado» ha sido la consecuencia de una autocrítica que los filósofos morales han tenido que autopropinarse no por gusto propio, sino debido a una creciente presión social. De hecho, creo que se podría suscribir que, en general, el gremio de los filósofos morales re-acciona cuando la amenaza de intrusismo se intensifica ante el silencio de una teoría ética enfrascada, por poner dos ejemplos bien representativos, o bien en el problema de la fundamentación de las normas -es el caso de las éticas del discurso- o bien en la dilucidación del significado del lenguaje moral - en la tradición analítica-. La apuesta por modelos fuertemente abstractos y formalizados, ajenos al aquí y al ahora de los contextos y circunstancias concretas, ha hecho de la teoría ética un territorio divorciado, a decir de algunos, de la realidad. La vuelta a los orígenes de la mano del repensar la praxis y de rehabilitar, en vena neoaristotélica, la necesidad de lo que Ricoeur llama la sagesse pratique ${ }^{3}$ se ha impuesto por la fuerza de los hechos. O abandonábamos la confortable torre de marfil o el barco se hundía.

No obstante, no se ha tratado de hacer borrón y cuenta nueva. La ganancia del procedimentalismo, de que las éticas contemporáneas tras los giros linguísticos y pragmáticos pertinentes, se hayan convertido en procedimentales nos puede ayudar a ofrecer modelos de juicio moral que dejen atrás las limitaciones individualistas. No es que la ética individual haya desaparecido o vaya a desaparecer, sino que sirve o es útil para una dimensión concreta - las relaciones interpersonales (de corto alcance) - , pero necesita ser relevada cuando atendemos a los problemas que son de muchos o de todos y que cada vez, aludamos a la socorrida globalización, son más. No sé si la analogía será la conveniente, pero al igual que la física newtoniana sigue funcionando en la estricta dimensión terrestre, Einstein demostró sus límites al enfrentar variables cósmicas. Sin irnos fuera del planeta, la complejidad del proceso que Max Weber designó como racionalización, la creación de

3 P. Ricoeur, «Le soi et la sagesse pratique: La conviction», en Soi-même comme un autre, Paris, De la Seuil, 1990, pp. 279-344. 
macroestructuras organizacionales, los efectos ampliados del modo de producción capitalista y las intervenciones tecno-científicas de efectos inciertos han colocado al objeto de consideración moral en una escala muchas veces ajena a la que contemplaban nuestros padres fundadores. Los problemas éticos ya no quedan circunscritos intramuros, en el interior de la polis, como le gustaba pensar a Sócrates. Igual que la física trabaja en diferentes escalas con diferentes marcos teóricos, a lo mejor, la ética debería olvidar el espejismo, sigo con el símil de la física, de la teoría unificada e intentar dar cuenta más ajustada del objeto a estudiar, de la esfera de actividad social o de la situación a evaluar moral y políticamente. A este respecto, creo que una cierta inflexión contextualista no puede ser desdeñada.

Sigamos con nuestro ejemplo, el deterioro medioambiental y la crisis ecológica apelan, directamente, a la humanidad toda. Esto es, y dejando claro que una parte de la humanidad - el Norte rico - corre con la responsabilidad de haber precipitado la situación actual, los afectados, en calidad de agentes y/o pacientes, somos absolutamente todos los nacidos e incluso todos los por nacer, esto es, las llamadas generaciones futuras. Las decisiones, como vamos viendo en las sucesivas Conferencias mundiales, por ejemplo, las que tratan del cambio climático, para ser efectivas deben ser tomadas por todos a la vez y sin trampa ni cartón - cosa que por ahora no se hace- La articulación de un «inter-sujeto» moral que circunscriba a la humanidad presente y futura es demandada, pues, por el problema mismo, puesto que su escala global e irreversible desarma e inhabilita el estrecho marco de una ética individual que se revela, frente a la magnitud del desafío impotente: aunque yo me comprometa a reducir las emisiones que yo provoco directamente, renunciando, por ejemplo, al transporte privado, al coche, el hecho de estar conectado a una red eléctrica que depende de una central a fuel, esto es, que quema combustibles fósiles, invalida todo efecto de mi acción. Salvaré mi conciencia y podrá embargarme la autosatisfacción del deber cumplido, pero lo que está claro es que no salvaré el planeta. El juicio moral para servir a una acción eficaz y responsable se debe articular intersubjetiva y colectivamente, debe pragmatizarse -fortaleciendo la sociedad civil- y como consecuencia concurrir al terreno de la política energética, cuestionando seguramente nuestras infladas «necesidades» y nuestro estilo de vida, no sólo local, ni nacional, sino global para pretender alguna efectividad, para pretender servir a una responsabilidad que exige la traducción de los juicios morales en acciones y hechos.

Dejo en el tintero que la articulación intersubjetiva del juicio moral debe contar con individuos que se hayan hecho la pregunta ¿de qué somos responsables? y que la hayan respondido enumerando algo más que su propio proyecto de autorrealización individual. Debemos contar con individuos concernidos por eso que Hannah Arendt llamaba el mantenimiento del «mundo», de la trama intersubjetiva que nos sostiene y que se renueva con 
cada nacimiento de un ser humano al que le debemos ofrecer memoria de lo ya acontecido como una suerte de legado. Esos mismos individuos, habitantes del espacio público y ciudadanos participativos, deben haber comprendido que el mismo «mundo» necesita estar enraizado en el mantenimiento de un metabolismo naturaleza-humanidad que hoy por hoy está amenazado por nuestro modelo de desarrollo económico depredador de la tierra que nos sostiene. La responsabilidad, acotada por Hans Jonas, de que siga existiendo en el futuro vida humana libre sobre la tierra es algo que debe importar al individuo y de lo que éste junto a todos los demás debe «hacerse cargo» ${ }^{4}$. Este tema nos remite al polémico asunto de la educación moral, puesto que los agentes socializadores de nuestro tiempo, sobre todo los medios de comunicación, apuestan en una dirección contraria: el enclaustramiento individualista que erosiona el «mundo» y el consumo compulsivo de bienes y servicios que arruina la tierra y empobrece todavía más a los más pobres. En este contexto cultural hoy por hoy hegemónico la llamada a la responsabilidad, como ya decíamos, cae en saco roto. Voy, por tanto, a continuación, a detenerme un poco más en explicar estos sentidos de la responsabilidad «ampliada» que nos proporcionan Arendt y Jonas.

\section{El juicio político: responsabilidad por el mundo común}

Mantener y preservar el mundo común en el que todo recién nacido debe integrarse es la responsabilidad que a todos nos concierne y por ello la reflexión de Arendt sobre la política queda anclada en consideraciones ontológicas que definen su originariedad frente a la idea liberal de la política como espacio de transacciones de intereses. Arendt vuelve al modelo de la polis griega para referirnos la experiencia política de la praxis que se revela a través de la acción y de la palabra. Si la esfera de la acción queda deshabitada, quedando sólo la del trabajo y la labor, el mundo común se hunde y se da paso a las diversas formas de totalitarismo destructor. La caracterización arendtiana de la acción como inicio, como efecto propulsor da cuenta de la irreversibilidad de la cadena de efectos que pone en marcha, a modo de bola de nieve que crece, y que muchas veces es imprevisible. Esta concepción de la acción es un punto de partida inevitable para toda ética de la responsabilidad. Por otra parte, la acción puede iniciarla uno, pero su continuación y mantenimiento es cuestión de muchos, de una pluralidad de individuos iguales y distintos.

Las reflexiones sobre la responsabilidad individual y colectiva son, en consecuencia, una constante en la obra de Arendt y cobrarán nuevas deter-

${ }^{4}$ M. Cruz, Hacerse cargo. Sobre responsabilidad e identidad personal, Barcelona, Paidós, 1999. 
minaciones en las que el «comprender» y la memoria serán determinantes. El modelo de juicio político en Arendt se alimenta de la teorización kantiana en la Crítica del Juicio. El modelo de la «mentalidad ampliada» en el que se nos exige ponernos en el lugar del otro para comprender su perspectiva y escapar de nuestro subjetivismo autista será su elemento vertebrador. Las propuestas de Arendt combinan, pues, elementos deontológicos y teleológicos en un razonamiento moral que incorpora la atención a los contextos a la vez que incide en un nuevo sentido de la responsabilidad que podemos categorizar como ontológico y político a la vez que se alimenta del mandato ético de preservar las redes de relaciones humanas frente a la amenaza totalitarista que necesita para arraigar de la desecación de la esfera pública en la que interactuamos a través de la palabra y la acción. Ésta es una nueva formulación de responsabilidad que tiene a su base el reconocimiento intersubjetivo y que, a mi entender, va más allá del individualismo de la noción normalizada de responsabilidad, de clara inspiración jurídica, como simple correlato de la libertad ${ }^{5}$. De hecho, Arendt acota una definición de responsabilidad colectiva relacionada con nuestra pertenencia a una comunidad dada, sea la que sea. El caso es que no podemos sustraernos ni a los logros ni a los fracasos colectivos de esa comunidad. A este respecto, la responsabilidad colectiva se diferencia de la culpa que sólo tendría una atribución puramente individual - la culpa singulariza y Arendt propone tratarla en el nivel estrictamente de la moral individual y de la legalidad-. Podemos abandonar una comunidad humana e ingresar en otra con lo que habremos cambiado una «carga» por otra. Arendt señala que la «inocencia» sólo se puede predicar de los refugiados y de la gente sin estado que no puede ser tenida por responsable políticamente de nada. Esta inocencia es infinitamente peor que la responsabilidad colectiva antes aludida porque destierra al aislamiento y a la marginalidad, y sitúa a los individuos fuera de la misma humanidad ${ }^{6}$. Basta con leer las páginas finales de Los Orígenes del Totalitarismo para comprobar ahora, en el caso de los «sin papeles» y de las políticas de extranjería, el acierto del diagnóstico de Arendt: sin Estado-nación que te respalde, sin estatuto de ciudadanía, la mera humanidad queda desnuda y desprotegida.

Este sentido de la responsabilidad colectiva creo que es coherente con la importancia que Arendt atribuye al «mundo», a la trama intersubjetiva en la que los individuos nos ensartamos a la hora de nacer. La natalidad impone hechos como el de la pertenencia que no pueden ser descartados por una comprensión romamente individualista. A esto responde la indicación de Arendt de que si te atacan como judía, deberás defenderte como tal y no

\footnotetext{
${ }^{5}$ Un tratamiento paralelo de esto lo podemos encontrar en cuanto a la distinción propuesta por Arendt entre objeción de conciencia y desobediencia civil.

${ }^{6}$ H. Arendt, «Collective responsability», en J. W. Bernauer (ed.), Amor mundi, Dordrecht, Martinus Nijhoff Publishers, 1987, pp. 43-50.
} 
acudir a un abstracto e inane concepto de humanidad. Prestar concreción y potencia al concepto de humanidad significa aceptar la pluralidad que la habita y que es la misma condición de la esfera de la política. La aspiración a la homogeneidad, del tipo que sea - cultural, lingüística, étnica- va pegada a los talones de los empeños totalitarios.

Sin poder demorarme más en la propuesta de Arendt podríamos destacar el intrínseco carácter intersubjetivo de estas dos acepciones de responsabilidad: de un lado, la de mantener las redes y vínculos que nos unen a los otros. Somos deudores de un legado y de una tradición, en un sentido de la responsabilidad que se expande hacia el pasado, esto es, debemos guardar memoria de lo acontecido y comprenderlo. Pero esa responsabilidad también se expande y amplía hacia el futuro asegurando a los que vienen la herencia de un legado que los haga entroncar con una herencia cultural dada. De esta responsabilidad de alguna manera originaria derivarían deberes concretos exigidos por un ideal de vita activa que alimente la esfera de la política, la esfera que trata de los asuntos de todos. Del otro, esa responsabilidad se concibe como colectiva al mostrar nuestra relación o deuda con una o unas comunidades humanas y con sus éxitos y fracasos. Esto conduciría a un sentido político - la moral para Arendt siguiendo a Aristóteles y a Cicerón es parte de la política porque trata de la vida del ciudadano- de la responsabilidad en la que:

La cuestión no es nunca si un individuo es bueno, sino si su conducta es buena para el mundo en el que vive. En el centro de interés está el mundo y no el yo ?.

Arendt nos lanza un desafío: ella alude a esta responsabilidad por el mundo como política porque define a la ética en términos estrictamente individuales. La política, en sus propios términos, concierne al mundo. Arendt objeta el dictum socrático de que lo importante es el estar a bien, en armonía, con uno mismo aunque no lo estemos con el mundo. Para ella más que garantizar la tranquilidad y el sosiego de la propia conciencia moral la clave de la cuestión se sitúa en la siguiente tarea:

Lo que es importante en el mundo es que no haya mal; tanto sufrirlo como hacerlo es igualmente malo. No importa quién lo sufra; tu deber es prevenirlo ${ }^{8}$.

Tras la redefinición intersubjetiva del mismo sujeto de la ética, por ejemplo, en las éticas del discurso no podemos ya aceptar la demarcación arendtiana entre la ética y la política. No obstante, las acotaciones de la misma Arendt apuntan al núcleo duro de la ética de la responsabilidad: no

${ }^{7}$ Op. cit., p. 46.

${ }^{8}$ Ibid. 
se trataría tanto de hacer el bien, sino de hacer todo lo posible por prevenir el mal ${ }^{9}$ - sea éste banal o radical-.

\section{La responsabilidad como principio de una ética ampliada: la naturaleza y las generaciones futuras}

Desde otro punto de vista, el libro de Jonas, El principio de responsabilidad, señala la necesidad del cuestionamiento del marco heredado de la tradición ética para enfrentar los nuevos desafíos que la degradación ambiental y el impacto de la tecnociencia sobre la naturaleza y la sociedad, desafíos que llegan a poner en duda hasta la permanencia de la especie humana sobre la tierra. La posición de Jonas es sui generis: de un lado, propone la extensión de la misma ética más allá del tradicional campo de las relaciones interhumanas para incluir a la naturaleza y a las generaciones futuras. Su concepto de responsabilidad no funciona ya como un correlato de la libertad, es decir, en términos subjetivos, sino que la define objetivamente en el sentido de que somos responsables del objeto, por ejemplo, de la conservación de la naturaleza. Su paradigma es la responsabilidad asimétrica de los padres hacia los hijos. Ese mandato incondicional de preservar la existencia y el futuro de la especie humana resuena en toda su obra. En este sentido, Jonas propone una nueva formulación de la responsabilidad como asunto colectivo y crucial frente a los desarrollos de la civilización científico-técnica. Con respecto al problema de la aplicación, Jonas articula una curiosa combinación de deontologismo y teleologismo. De un lado, mantiene que los nuevos problemas de la degradación ambiental y la manipulación genética exigen que detectemos nuevos principios morales anticipando nuevas situaciones. Del otro, estas nuevas coyunturas nos demandan ir detallando una suerte de casuística de la imaginación, atenta a las consecuencias, de la que los nuevos principios puedan ser tanto extraídos como aplicados. Jonas, pues, exige la pertinencia ética de ambos enfoques. Si Weber y Arendt quedaban anclados en la preocupación política, de maneras harto diferentes, Jonas va a problematizar las carencias teóricas de los enfoques éticos tradicionales al contrastarlos con las necesidades de una ética (aplicada) que atienda al impacto de la tecnociencia en la naturaleza (ética ecológica) y en los seres humanos (bioética).

Hoy la técnica se ha convertido en objeto de la ética ${ }^{10}$, no sólo en tanto en cuanto es un tipo más de acción humana, sino por ser un «caso especial». A este respecto alega cinco razones que justifican el desafío de la técnica

\footnotetext{
${ }^{9}$ El que no se repita Auschwitz, el imperativo que formula Adorno resuena en el dictamen de Arendt igualmente. Cfr. M. Tafalla, Theodor W. Adorno. Una filosofia de la memoria, Barcelona, Herder, 2003.

${ }^{10}$ Hans Jonas, «Por qué la técnica moderna es objeto de la ética», en Técnica, medicina y ética. Sobre la práctica del principio de responsabilidad, Barcelona, Paidós, 1997, pp. 33-37.
} 
moderna a la ética tradicional: 1) «ambivalencia de los efectos» ${ }^{11}$-tesis que podemos correlacionar con la de los «efectos colaterales» de Beck-; 2) «automaticidad de la aplicación» que implica que las capacidades técnicas adquiridas, en nuestras sociedades, no puedan «reposar», sino que se expanden pasando «a la corriente sanguínea de la acción colectiva, de la que ya no se pueden separar» ${ }^{2}$; 3) su actuación a gran escala - tanto en las dimensiones espaciales como en las temporales-que, incluso, puede empequeñecer el escenario de su despliegue, la misma tierra, y que deja en suspenso qué bien podrá proporcionar a los seres humanos actuales $\mathrm{y}$, dada su persistencia en el tiempo, a los futuros; 4) la devastación producida - real o posible - por las posibilidades técnicas pone en cuestión la limitación antropocéntrica de la ética haciéndonos revisar los modos de la relación que mantenemos con todo aquello que tiene un fin en sí mismo, los seres naturales y la naturaleza misma ${ }^{13}$; 5) finalmente, Jonas se desliza, empujado por las implicaciones del desafío técnico, desde la ética hasta la metafísica planteándonos si la existencia de la humanidad es un imperativo categórico que prohíbe todo juego suicida y que regularía

cuánto podemos arriesgar admisiblemente en nuestras grandes apuestas técnicas y qué riesgos son del todo inadmisibles ${ }^{14}$.

La responsabilidad para Jonas es, por tanto, sustantiva, no formal. No se trata de que seamos responsables de nuestros actos y podamos ser juzgados como inocentes o culpables. Somos responsables de la existencia y el cuidado de los objetos - la responsabilidad enraíza en la ontología-. El paradigma de este modelo de responsabilidad es la parenthood - la paternidad-maternidad- que implica la preocupación por la existencia y el desarrollo de los hijos e hijas. Se trata de que nos hagamos cargo de poner las condiciones de posibilidad para que nuestros niños tengan un futuro. Nuestra responsabilidad implica cuidado de los otros dependientes y preservación de sus posibilidades vitales. Extrapolando este paradigma de la responsabilidad «objetiva» nos encontramos con la exigencia de garantizar «las condiciones para que la vida exista en el futuro» ${ }^{15}$.

\footnotetext{
11 «QQué ocurre cuando nos movemos en un contexto en el que cualquier uso de la capacidad a gran escala, por muy buena que sea la intención con que se acomete, lleva consigo una orientación con efectos crecientes en última instancia malos, que están inseparablemente unidos a los "buenos" efectos perseguidos y al alcance de la mano y al final quizá los superen en mucho?», op. cit., p. 33.

12 Op. cit., p. 34.

13 El monismo jonasiano se rebela primero contra el dualismo idealista predominante desde Descartes en la modernidad y pretende repensar, en palabras de Leo Kass, tanto «la continuidad y la especial discontinuidad de lo humano dentro del dominio de lo vivo». L. Kass, «Appreciating The Pheno menon of Life», Hasting Center Report, núm. 7, Special Issue, 1995, pp. 3-12, especialmente p. 4.

14 H. Jonas, op. cit., p.37.

15 R. Bernstein, art, cit., p. 841.
} 
La «heurística del temor» arbitra, en consecuencia, una suerte de proceder negativo ${ }^{16}$. La orientación hacia el futuro de la ética nos obliga a procurar la representación de los efectos remotos y a apelar a los sentimientos que suscita lo representado. Si la representación operada por la imaginación se resuelve en temor, podremos habilitar una especie de empatía con los hombres y mujeres del porvenir, por las condiciones futuras de su existencia. La responsabilidad enraíza como sentimiento en la naturaleza humana. El emotivismo jonasiano recupera, de este modo, el papel de los sentimientos morales y de la imaginación al servicio de la constitución de una representación de lo posible que nos habilite para poder atisbar «unos principios morales hasta el momento desconocidos por innecesarios». Sentimiento, imaginación y reflexión se alían para trabajar sobre la incierta materia de lo posible, de lo futurible. Por esta razón, se impone la «vigilancia en los comienzos»: una vez que la bola de nieve comience a girar no sabemos dónde parará ni podemos prever la magnitud del destrozo que provocará. Jonas asume las determinaciones de la acción que propone Hannah Arendt en La condición huma$n a{ }^{17}$. No obstante, nuestra responsabilidad incluye lo lejano y este cuidarnos del futuro delimitará la apuesta que toda acción humana contiene respecto de su desenlace y efectos colaterales.

Jonas, y ésta es una característica que comparte con Arendt, es uno de los pensadores que no hace ascos a ensañarse con la unilateral y peligrosa glorificación del progreso al tiempo que repudia la ensoñación utópica del paraíso por venir a la tierra. Se excluyen, por tanto, los grandes riesgos de la tecnología en nombre del falaz dogma del progreso, una idea que responde a la arrogancia prometeica de la civilización tecnológica. Ninguna vana promesa puede justificar el jugar con el interés de la humanidad futura. Se formula así un derecho y un deber incondicional de la humanidad para con la existencia. Nuestro deber es preservar, cuidar, porque el hombre, más que como creador, se ha revelado como destructor. La amenaza a conjurar es la que aspira a arruinar a la misma indeterminación como atributo de lo humano. Nadie puede arrogarse el poder de «clausurar», de «cerrar» el futuro constriñéndolo a una sola opción. Desde esta advertencia se entiende el antiutopismo jonasiano y su repudio de las ideas tecnofílicas de mejoramiento eugénesico ${ }^{18}$

16 Jonas, debido a su formación teológica, sabe que el conocimiento del malum es infinitamente más fácil que el del bonum. La mera presencia del mal nos impone su conocimiento. Si conocemos el bien es mediante el «rodeo del mal». La filosofía moral tiene que consultar antes a nuestros temores que a nuestros deseos. Jonas va a condenar sin contemplaciones el pathos utópico frente a la única urgencia tangible la de la supervivencia. La heurística del temor si no tiene la última palabra en la búsqueda del bien, sí tiene el dudoso privilegio de emitir la primera. Jonas fue un estudioso del gnosticismo, uno de sus grandes maestros fue Rudolf Bultmann. Algunos de sus escritos de corte teológico pueden encontrarse recopilados en H. Jonas, Mortality and Morality. A Search of God after Auschwitz, Northwestern University Press, 1996.

17 H. Arendt, La condición humana, Madrid, Seix Barral, 1974.

18 Cfr. H. Jonas, «Hagamos un hombre clónico: de la eugenesia a la tecnología genética» y «Microbios, gametos y cigotos: más sobre el nuevo papel creador del ser humano», en Técnica, medicina y ética, op. cit., pp. 109-134 y 135-143. 
y de autofabricación consciente de lo humano. Diciéndolo en arendtiano de lo que se trataría es de preservar la posibilidad que viene al mundo con cada ser humano, la natalidad, la posibilidad de un nuevo comienzo, de muchos posibles comienzos. Contra lo que se mantiene el principio de responsabilidad, invocando, por ejemplo, los derechos de las generaciones futuras, es contra el imperativo del dominio del de la vida porque la vida implica la responsabilidad de preservarla y de transmitirla a los recién llegados, a los niños, y a los por venir. Indeterminación y apertura son las claves del peculiar y sui generis preservacionismo jonasiano. La invocación a la responsabilidad presente se troca en garante de la libertad futura. La «libertad tecnocientífica» desatada puede anular la misma posibilidad de la libertad humana. Asignemos al desastre posible la contundencia de la certeza para que esta operación nos disuada de la tentación de apostar lo finito con tal de alcanzar lo infinito. Jonas parece presentar otra versión del horror vacui: frente a la nada que se asume como riesgo, la fugaz existencia temporal de lo humano posee una magnitud infinita. El deber primario nos exige optar por el ser frente a la nada en franco desafío a la tentación nihilista.

\section{Juicio moral y responsabilidad: más allá de la prudencia}

La pregunta que irrumpe a estas alturas, después de haber vislumbrado nuevas dimensiones de la responsabilidad, es la siguiente: ¿Cómo deben articularse los juicios morales para estar a la altura de las circunstancias en lo que respecta a las demandas de una responsabilidad «ampliada»?

Lo primero que deberíamos decir es que, a mi entender, una ética de la responsabilidad va más allá, sobrepasa la antítesis entre enfoques estrictamente deontológicos - los que remiten al mero deber y a la aplicación deductiva de los principios- y enfoques estrictamente consecuencialistas - algunos utilitarismos, por ejemplo, los que denominamos del acto-. Ambos se muestran insuficientes. También la responsabilidad, a pesar de estar emparentada con la prudencia, va más allá de ésta. Acoge la prudencia porque estima que las circunstancias y los casos concretos no son extrínsecos al objeto de consideración, sino que lo determinan y, por tanto, deben ser contemplados en la ponderación, en el sopesar deliberativo, que es el proceder del juicio moral mismo. Pero aspira a ser algo más que prudencia y esto sólo lo puede hacer incorporando una dimensión normativa que sirva, si no para determinar fijamente el resultado del juicio haciendo derivar a éste del principio al modo del juicio determinante kantiano, sí para orientarlo. Por otra parte, otra constatación que no debemos desoír es que diversos principios pueden, y suelen, entrar en conflicto en las situaciones concretas con lo que la dilucidación moral del juicio no admite automatismos de ningún tipo. 
Un modelo intersubjetivo y pragmático, por llamarlo de alguna manera, de juicio moral que nos puede, tentativamente, servir para cubrir estas exigencias podría articularse al menos en estas fases y atender a los siguientes elementos. Eso sí, todos interactuarán con todos y exigirán la colaboración de nuestras facultades morales - sentimientos, imaginación, razón- y de las ineludibles virtudes comunicativas que se necesitan en la apertura al diálogo y a la controversia:

\section{Percepción moral del problema.}

Dilucidar qué requiere atención moral, y qué no, no es un asunto tan sencillo como podría parecer. Asuntos que hasta hace poco estaban fuera del punto de mira de la moral, de repente, se revelan y exigen atención ética. Requiere, además, de instrumentos para hacernos cargo del tratamiento moral de la particularidad. El problema ecológico nos vuelve a servir de ejemplo: antes del certero diagnóstico de Rachel Carson acerca de los efectos nocivos de la contaminación en Primavera Silenciosa no podíamos hablar de que la relación con la naturaleza fuera un problema moral. Su denuncia de nuestra civilización biocida y suicida es la que nos hizo abrir los ojos a la barbarie de la que somos cómplices y de este modo transitó desde la sensibilidad naturalista a la conciencia ecológica. Determinar los elementos que colaboran a la percepción moral de los problemas es una tarea compleja a la que no es ajena nuestra sensibilidad modelada por factores históricos y sociales. Otro ejemplo de esto sería el fenómeno de la violencia doméstica, que habiendo existido siempre, sólo desde hace poco tiempo se analiza como problema moral de dimensiones sociales que va más allá de las concretas conductas individuales y requiere respuestas políticas e institucionales.

Por otra parte, tratar del asunto de la percepción moral nos permite plantearnos qué falla cuando los individuos o las sociedades son insensibles frente a problemas tales como la violencia, la falta de libertad, la injusticia, etc. Arendt en su análisis del caso Eichmann acusaba a la incapacidad para pensar representativamente, para ponerse en el lugar del otro, otros autores completan su visión refiriéndose a la falta de empatía y al entumecimiento de los sentimientos y emociones morales que nos suelen dar la voz de alarma ante las tropelías. Éstos señalan que algo va mal y merece atención ética. Una pregunta que con respecto a este asunto de la percepción moral no podemos dejar de hacernos, y que nos sume en cierta perplejidad, es hasta qué punto somos responsables del adormecimiento de nuestra capacidad perceptiva al detectar conflictos morales. ¿Hasta qué punto la indiferencia es culpable?

2. Análisis y estimación de los hechos.

Una vez detectado el problema queda formularlo y analizarlo. Los asuntos sobre los que emitir un juicio moral en nuestro presente son cada vez 
más complejos. Pongamos algunos ejemplos más allá del de la degradación del planeta: las consecuencias de la revolución genómica, las aplicaciones de las nuevas tecnologías de reproducción, el efecto de la violencia en los medios de comunicación sobre los niños, las modalidades de la ganadería y la agricultura y sus efectos en nuestra salud, etc. Todos estos temas presentan un alto grado de «polemicidad» y son objeto de controversia. Su tratamiento requiere de colaboración interdisciplinar porque ninguna disciplina es capaz de dar cuenta de esta complejidad de los diversos impactos ecosociales por sí sola. Dada su relevancia pública, además, no deben ser dejados sólo en manos de «expertos» una vez caída en desgracia la idea de la neutralidad axiológica de la ciencia, puesto que ésta está también tejida por intereses. La ciudadanía debe incorporarse y hacer suyo el debate y, por lo tanto, se requiere de un proceso de «ilustración» ecológica, científica, social que haga que los legos en la materia puedan estar bien informados, para después de deliberar poder decidir. Si vamos a correr riesgos, al menos que nos den la oportunidad de decidir si queremos o no correrlos.

\section{Orientaciones normativas.}

A pesar de que las críticas a la aplicación automática de los principios morales a la realidad son certeras, a este respecto podríamos invocar al mismo Aristóteles o a Jeremy Bentham, no es posible prescindir de orientaciones normativas enraizadas en nuestros consensos acerca de lo que es valioso preservar. Ese marco normativo hoy remite a los Derechos Humanos, a sus ampliaciones, y, también, a las aproximaciones críticas a los que se les somete. Los marcos normativos se ven ampliados por los problemas emergentes: la tercera generación de derechos, en concreto, el derecho a un medioambiente saludable no se le hubiera ocurrido a nadie sin la eclosión de la crisis ecológica treinta años atrás. A nadie escapará, también, que a este nivel normativo el conflicto está servido: la preservación de la libertad puede colisionar con el anhelo de justicia e igualdad o el derecho a la intimidad con las exigencias de la salud pública. El caso es que estimar el conflicto entre principios éticos, decidir su rango para otorgar prioridad a uno de ellos o intentar su compatibilización es otro gran problema a no descartar, puesto de manifiesto por Weber y su imagen del politeísmo de los valores.

4. Estimación de consecuencias.

Las orientaciones normativas deben conjugarse con la tarea, igualmente complicada de la estimación de consecuencias. La imaginación moral es una facultad esencial a este respecto. El problema del riesgo ha hecho correr ríos de tinta en diferentes ámbitos. ¿Debemos cómo opina Jonas imaginar el peor escenario imaginable para orientar nuestros juicios morales? ¿Debemos, pues, curarnos en salud? El caso es que, dada la renuencia a aplicar el llamado principio de precaución, los riesgos, derivados de la incertidumbre, se 
multiplican muchas veces como efectos colaterales o perversos de acciones planificadas como beneficiosas. Las aproximaciones casuísticas son invocadas a este respecto para moderar la tentación de aplicar siempre la misma resolución a casos diferentes. Los enfoques teleológicos siempre han dado protagonismo a este nivel de análisis y parece ser imprescindible a una ética de la responsabilidad que respire en la actividad de enjuiciar moralmente de forma atinada.

5. Crítica de los valores sociales dominantes.

Por último, a estas alturas, parece conveniente no dejar de prestar una atención especial a la crítica cultural y social en lo que respecta a las inercias que obturan y paralizan la misma actividad del juicio moral. El diagnóstico de los riesgos y amenazas debe servir para objetar determinados consensos sociales que impiden el tomarse en serio la responsabilidad de atender a las urgencias éticas del presente. A este respecto, el deber que se deriva de aquí es el de promover espacios dialógicos que cuestionen y objeten las definiciones hegemónicas de la realidad, foros donde se pueda contraargumentar contra la autocomplacencia del statu quo y su creencia implícita de que vivimos en el mejor de los mundos posibles. Los emergentes foros antiglobalización podrían servir de ejemplo de lo que ahora es un deber: denunciar los efectos injustos de los modelos económicos, sociales y culturales que impone el stablishment. El agotamiento del pensamiento utópico no tiene por qué traer consigo la aceptación de lo que ocurre como inevitable. Señalar el mal y la injusticia está en nuestra mano, como, también, lo está imaginar alternativas para frenar las desigualdades y maltratos que ocurren todos los días. No se si éste podría ser el sentido de una responsabilidad negativa que más que imaginar el cielo pugna por eliminar los diversos infiernos que nos rodean. De ellos, por su magnitud, el abismo que separa al rico Norte del empobrecido Sur no es el menor y, por tanto, requeriría más de nuestra atención moral y política. Una sociedad civil y una opinión pública internacional deben ser forjadas para tratar críticamente con el marco de la globalización económica y política ${ }^{19}$.

Este último punto incide, de nuevo, en que ante la magnitud ampliada de la acción humana - económica o tecnológica - tenemos que dar una respuesta también «ampliada» no sólo de la formulación de la responsabilidad en sus dimensiones intersubjetivas y objetivas, sino que, a través de una reconsideración del juicio moral y político, debemos articular modelos pragmáticos que nos permitan dar cuenta de la complejidad del mundo en el que vivimos y de los retos de largo alcance que nos plantea el presente. El caso es que, a través de nuevos modelos de juicio moral que combinen lo mejor de las tradiciones deontológicas - como la kantiana - y teleológicas - como

${ }^{19}$ Cfr. C. Ortega y M. J. Guerra, Globalización y neoliberalismo: ¿un futuro inevitable?, Oviedo, Nobel, 2002. 
la aristotélica y la utilitarista-, tenemos la esperanza de poder transitar, arbitrando mediaciones, sensibles a los diversos contextos y escalas, de lo teórico a lo práctico y viceversa -de los principios abstractos a los casos concretos en viajes de ida y vuelta- y trabajar para anular, también, la desconexión entre la teoría ética y las aplicaciones. Necesitamos una procedimentalización del juicio moral para poder enfrentar los asuntos candentes y atender a las circunstancias concretas en las que los problemas aparecen. Justo esto es lo que demandan las distintas variedades de ética aplicada (bioética, ética ecológica, de economía, de la información, de las profesiones...) y los problemas acuciantes que tratan (revolución genómica, medidas ante el calentamiento de la atmósfera, desigualdad social, impacto de los medios de comunicación, deontologías profesionales...). En consecuencia, lo que parece que se impone, a partir de los desarrollos de la ética aplicada, es la emergencia de un nuevo paradigma integrador, todavía por desarrollar y armar, en el que la prioridad se le asigne a la idea moral de responsabilidad. El grado de «acierto» de los juicios morales, que son los que deben inspirar la acción, será evaluado por su carácter responsable. Esto, a mi parecer, obliga a una inflexión de carácter negativo, porque más que pensar su adecuación con el bien deberemos primar, y asegurarnos, en la medida de lo posible, de que evita el mal, o por qué no, lo remedia, lo mitiga, lo hace languidecer. Si tomamos como signo y síntoma el imperativo adorniano de que «Auschwitz no se repita», el énfasis se colocará en la evitación del exterminio de la humanidad más que en la persecución de ideales utópicos de sociedades idílicas que suelen descontar a la misma condición humana y sus servidumbres. Algo se ha quebrado en el siglo Xx, quizás la confianza mesiánica en el progreso, y esta quiebra remite a que el punto de toque de la nueva ética de la responsabilidad sea la exigencia de la supervivencia, tal como hace más de tres décadas planteaba Apel. Evitar la tragedia es la consigna de la ética de la responsabilidad que, quizás, es la única que responde al diagnóstico contemporáneo de la «sociedad del riesgo» y a las demandas de un mundo que ha redescubierto el reto lanzado por el pluralismo ante la presencia de una vorágine de situaciones inéditas. 